\title{
A Cross-Sectional Study to Assess Awareness and Practices Related to Prevention of COVID-19 Amongst Local Vendors around Medical and Dental Establishments
}

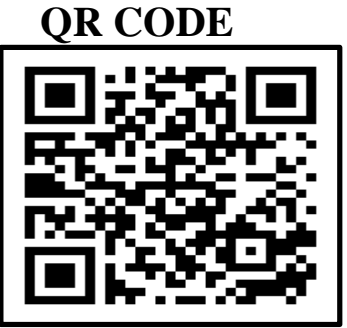

\author{
NEIL SHARMA', AAKRITI BHATNAGAR*2, S. VASUDEV3, ANAMIKA KOHLI3
}

INTRODUCTION: Even as the world is returning to normalcy after COVID-19, there is still a need to be cautious and adopt proper hygiene practices and social distance norms.

AIM: To assess the awareness and practices related to prevention of covid-19 amongst local vendors around medical and dental establishments in Northern India.

MATERIALS AND METHOD: This cross-sectional study was conducted over a period of one month using a pre-tested and pre-validated questionnaire. Vendors near ten medical and dental establishments in north India were contacted by standardized volunteers to prevent bias. They were located within the range of $\mathbf{2 5 0}$ meters on both sides of these facilities through convenience sampling. Data was coded, entered in MS excel, descriptive statistics were applied. Statistical tests included the student's independent $\mathrm{t}$-test and multiple logistic regression. $\mathrm{P}$ value was kept significant at $<0.5$ and software used was SPSS version 23.0.

RESULTS: Most vendors were males $(76.7 \%)$, were operating shops on rent $(47.7 \%)$ and had passed middle school $(40.2 \%)$. A Majority of them were aware of common symptoms $(99.4 \%)$, while $90.1 \%$ were aware about the mode of transmission. All vendors knew about the availability of the vaccine $(100 \%)$. and $78.2 \%$ of the vendors were fully vaccinated, while $04(1.3 \%)$ were not vaccinated yet. However, only $60 \%$ ( $\mathrm{p}=0.03$ ) of the vendors practised hand washing, distancing from sick, no handshake, use a cloth while coughing/sneezing as preventive measures.

CONCLUSION: There is still a need for continuous education of the food vendors regarding proper and hygienic practices as well as mask wearing to fight off this dreaded pandemic and return to normalcy as soon as possible.

KEYWORDS: Vendors, Covid-19, Hygiene, Masks, Compliance

\section{INTRODUCTION}

The human race has been witness to numerous epidemics and pandemics which have affected millions of lives, either resulting in morbidity or mortality. Even as we humans boast of numerous advances in medicinal and allied research, the threat of new, undefined pathogens that pose an invisible threat to human lives. The Severe Acute Respiratory Syndrome Coronavirus-2 (SARS-CoV-2) is a novel coronavirus that had brought the human life on a standstill and several parts of the globe were staring at a global, economic and healthcare system(s) related crisis. ${ }^{1}$

With the world returning to normalcy, thanks to the combined efforts of all healthcare workers, men and women in uniform and researchers who developed the vaccine to combat this deadly virus, there is still a need to maintain proper precautionary measures and social distancing norms. In addition, a correct knowledge of preventive measures and practicing respiratory hygiene is utmost important to break the chain of transmission. This can be achieved through frequent communication between health care providers and the public. $^{2}$

The nature of the work profile of these vendors puts the vendor at risk of either being affected with the disease, or serving as a potential carrier of this virus. They need to be in constant contact with people, and handle the exchange of currency and it has been scientific studies have shown the potential of a virus and norovirus to be transmitted through banknotes and coins. ${ }^{3}$ In a study done in India, $42.3 \%$ of the vendors opined that it is difficult for an ordinary road side food vendor to provide cent percent quality, hygienic \& nutritious food and a majority of the vendors were not using soap for washing hands. ${ }^{4}$

Keeping the above facts in mind, it is important that in a post COVID-19 world, street vendors pay proper attention to proper and safe hygienic practices to prevent the further spread of this disease. Hence, the present study was undertaken with the aim to assess the awareness and practices related to prevention of Covid-19 amongst local vendors around

(C) Neil Sharma et al. This is an open access article distributed under the terms of the Creative Commons Attribution License CC-BY-NC 4.o, which permits unrestricted use, distribution and reproduction in any medium, provided the use is not commercial and the original author(s) and source are cited. Submitted on: 04-Aug-2021; Accepted on: 26-Dec-2021 
medical and dental establishments in Northern India.

\section{MATERIALS AND METHOD}

The present study was designed to be cross-sectional in nature, conducted over a period of one month (July 2021-August, 2021) using a pre-tested and pre-validated questionnaire adopted from Shastri et al. and obtaining a proper ethical clearance. 5 Vendors near ten medical and dental establishments in north India were contacted and data was collected by the standardized interviewer in hindi. To avoid social desirability bias, no personal data of the respondent were collected. Also, data was collected by standardized volunteers not associated with the study to prevent interviewer's bias. Vendors located within the range of 250 meters on both sides of these facilities were included in the study using convenience sampling.

Data collected was coded, entered in MS excel, descriptive statistics were applied. Statistical tests included the student's independent t-test and multiple logistic regression. P value was kept significant at $<0.5$ and software used was SPSS version 23.0. ${ }^{6}$

\section{RESULTS}

The demographic details of the vendors is depicted in table 1. Most vendors were males $(76.7 \%)$, were operating shops on rent $(47.7 \%)$ and had passed middle school $(40.2 \%)$. The least of graduated were vendors were graduates $(11.0 \%)$. $21.8 \%$ of the vendors were employees and were working for someone else.

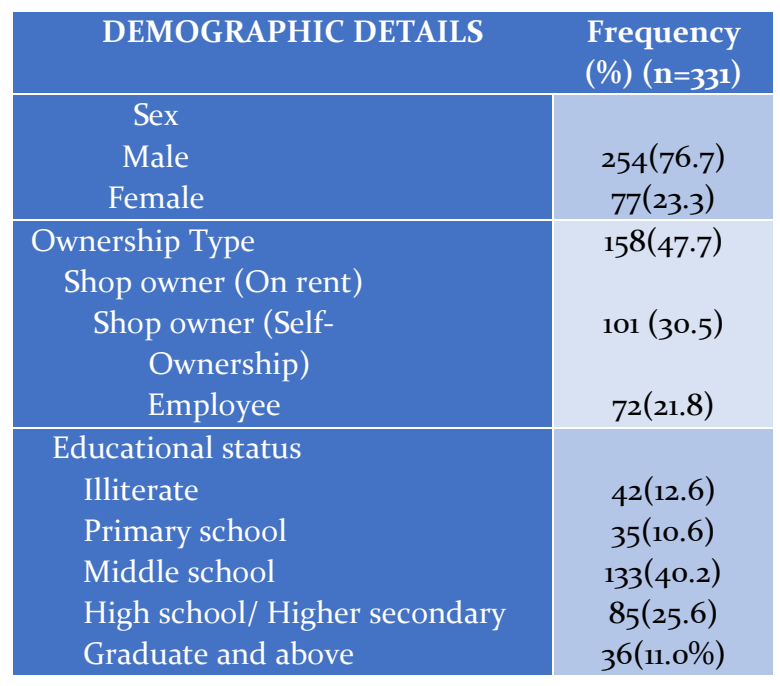

Table 1. Demographic details of the vendors
Significant responses of the vendors to the questionnaire is depicted in table 2. It was observed that most vendors are aware of common symptoms (99.4\%, $\mathrm{p}=0.01)$, while $90.1 \%(\mathrm{p}=0.03)$ were aware about the mode of transmission. All vendors knew about the availability o the vaccine $(100 \%, \mathrm{p}=0.02) .78 .2 \%$ of the vendors were fully vaccinated, while $04(1.3 \%)$ were not vaccinated yet. However, only $60 \%(\mathrm{p}=0.03)$ of the vendors practised hand washing, distancing from sick, no handshake, use a cloth while coughing/sneezing as preventive measures.

While observing the responses of the vendors regarding their practices (table 3), most vendors reported having their source of information from internet and media (57.1\%, $\mathrm{p}=0.03$ ), and fortunately, while reporting hand washing practices, most vendors reported that they washed their hands very often (44\%), and this was found to be significant $(\mathrm{p}=0.03)$. It was observed that $35.9 \%$ of the vendors wore their masks occasionally followed by $32.7 \%$ vendors were reported to wear their masks, although it was placed below their nose. These differences in mask wearing was also found to be statistically significant.

\section{DISCUSSION}

The results of the present study, based on the aim of assessing the awareness and practices related to prevention of Covid-19 amongst local vendors around medical and dental establishments in Northern India revealed a need for better education of the vendors to better control and prevent the spread of the pandemic as they are often in contact with the general population; an at places like bus stands and railway stations, they often come in contact with those travelling from all corners of the country; and thus making them vulnerable without adopting proper hygienic practices.

A majority of the vendors were males (76.7\%), and this is in agreement as per the study findings of Thakur CP et al. ${ }^{7}$, who reported a prevalence of $97 \%$ male vendors. However, in contrast, among studies conducted by Mohamed A et al. ${ }^{8}$ (72\%) and Nkosi NV et al. ${ }^{9},(73.4 \%)$ females vendors formed a majority as vendors. These findings are dependent of various factors, a few of them being the local beliefs, geographic location and presence of basic facilities around these vendors.

An encouraging fact was that $99.4 \%$ of the vendors were aware of the common symptoms of Covid-19. This is agreement to studies conducted by various 


\begin{tabular}{|c|c|c|}
\hline & Frequency (\%) & p-value \\
\hline Are aware of common symptoms & $329(99.4)$ & 0.01 \\
\hline Aware about mode of transmission & $301(90.1)$ & 0.03 \\
\hline $\begin{array}{l}\text { Practised hand washing, distancing from sick, no handshake, use a cloth } \\
\text { while coughing/sneezing }\end{array}$ & $199(60.1)$ & 0.03 \\
\hline Knew about availability of vaccine & $331(100.0)$ & 0.02 \\
\hline $\begin{array}{l}\text { Vaccination Status } \\
\text { Fully Vaccinated } \\
\text { Partially Vaccinated } \\
\text { Not Vaccinated Yet }\end{array}$ & $\begin{array}{c}259(78.2) \\
68(20.5) \\
04(1.3)\end{array}$ & $\begin{array}{l}0.01 \\
0.02 \\
0.04\end{array}$ \\
\hline Elderly age group is most affected by this virus & $283(85 \cdot 5)$ & 0.01 \\
\hline
\end{tabular}

Table 2. Significant responses to the questionnaire

authors. ${ }^{5,10,11}$ This could be due to the reason that the medium of knowledge dissemination has increased in general, ranging from newspapers to smartphones. In our study, most vendors (57.1\%) got their knowledge regarding COVID-19 from Internet and social media, whose use was quite prevalent during the nation-wide lockdown.

\begin{tabular}{l|c|c|}
\multicolumn{1}{|c}{ PRACTICES } & $\begin{array}{c}\text { FREQUENCY } \\
(\%)\end{array}$ & $\begin{array}{c}\text { p- } \\
\text { value }\end{array}$ \\
\hline Source of information & & \\
Family, relatives and & $53(16.1)$ & \\
friends & $89(26.8)$ & 0.03 \\
Media & $189(57.1)$ & \\
Internet and social media & & \\
\hline Hand Washing Practices & & \\
$\quad$ Never & $33(9.9)$ & \\
Before eating & $56(16.9)$ & \\
Sometimes & $88(26.5)$ & 0.03 \\
After every customer & $9(2.7)$ & \\
Very often & $145(44)$ & \\
\hline Mask Wearing among & & \\
vendors & & \\
Not Wearing & $52(15.7)$ & \\
Wearing Mask, but & $108(32.7)$ & 0.02 \\
below nose & & \\
Occasional Mask & $119(35.9)$ & \\
wearing & $52(15.7)$ & \\
Wearing all the time & & \\
\hline
\end{tabular}

Table 3. Practices related to prevention of COVID19 by the vendors

It was also overwhelming to know that all vendors knew about the availability of vaccine (100\%). In addition, $78.2 \%$ vendors were fully vaccinated, while $20.5 \%$ of them took the first dose of the vaccine. However, efforts should be made to encourage the remaining $1.3 \%$ of vendors who have not started their vaccinations yet.

It was observed that $35.9 \%$ of the vendors wore their masks occasionally followed by $32.7 \%$ vendors were reported to wear their masks, although it was placed below their nose. Similar findings were reported by et al. who reported that $85 \%$ of males and $87 \%$ of females were only wearing masks; thus indication that even after educating the general public at various levels, total mask compliance by the population is yet to be achieved.

\section{CONCLUSION}

Based on the results of the previous study there is still a need for continuous education of the food vendors regarding proper and hygienic practices as well as mask wearing to fight off this dreaded pandemic and return to normalcy as soon as possible.

\section{REFERENCES}

1. Nour C, Sana C, Reina B, Ali S, Abdallah A, Mohamad $\mathrm{R}$, et al. COVID-19: A Multidisciplinary Review. Frontiers in Public Health 2020; 8:383. https://doi.org/10.3389/fpubh.2020.00383 2. Gohel KH, Patel PB, Shah PM, Patel JR, Pandit N. Knowledge and perceptions about COVID-19 among the medical and allied health science students in India: An online cross-sectional survey. Clin Epidemiol Glob Heal https://doi.org/10.1016/j.cegh.2020.07.008 3. Angelakis E , Azhar EI , Bibi F , et al . Paper money and coins as potential vectors of transmissible disease. Future Microbiol 2014;9:249-61. https://doi.org/10.2217/fmb.13.161

4. Reang $\mathrm{T}$, Bhattacharjya $\mathrm{H}$. Knowledge of hand washing and food handling practices of the street food vendors of Agartala, a north eastern city of India. 
Journal of Evolution of Medical and Dental Sciences 2013;2(43):8318-23.

5. Shastri S, Bhatnagar D. A Cross-Sectional Study to Assess Awareness and Practices Related to Prevention of COVID-19 amongst Shopkeepers near Medical Establishments. Natl J Community Med 2021;12(3):4852. https://doi.org/10.5455/njcm.20210216052351

6. IBM Corp. Released 2015. IBM SPSS Statistics for Windows, Version 23.0. Armonk, NY: IBM Corp.

7. Thakur CP, Mehra R, Narula C, Mahapatra S, Kalita TJ. Food safety and hygiene practices among street food vendors in Delhi, India. International Journal of Current Research 2013;5(11):3531-4.

8. Mohamed A, Suliman S, Amel B. Food safety knowledge and practices of street food- vendors in Atbara City (Naher Elneel State Sudan). African Journal of Biotechnology. 2009;8:6967-71.

9. Nkosi NV, Tabit FT. The food safety knowledge of street food vendors and the sanitary conditions of their street food vending environment in the Zululand
District, South Africa. Heliyon 2021; 7(7):eo7640, https://doi.org/10.1016/j.heliyon.2021.eo7640 10. Wolf MS, Serper M, Opsasnick L, O'Conor RM, Curtis L, Benavente JY, et al. Awareness, Attitudes, and Actions Related to COVID-19 Among Adults with Chronic Conditions at the Onset of the U.S. Outbreak: A Cross-sectional Survey. Ann Intern Med. 2020;173(2):100-9. https://doi.org/10.7326/M20-1239 11. Roy D, Tripathy S, Kar SK, Sharma N, Verma SK, Kaushal V. Study of knowledge, attitude, anxiety \& perceived mental healthcare need in Indian population during COVID-19 pandemic. Asian J Psychiatr [Internet]. 2020;51. https://doi.org/10.1016/j.ajp.2020.102083

12. Rathod A, Modaboyina S, Agrawal S, Saluja G, Sharma N, Das Deepsekhar. Assessment of compliance and adherence to wearing masks and perceived severity and susceptibility of acquiring COVID-19 in patients reporting to an ophthalmology casualty in India, Indian Journal of Ophthalmology 2021; 69(6):1631-2. https://doi.org/10.4103/ijo.IJO_2931_20

Cite this article as:

Sharma N, Bhatnagar A, Vasudev S, Kohli A. A Cross-Sectional Study to Assess Awareness and Practices Related to Prevention of COVID-19 Amongst Local Vendors around Medical and Dental Establishments. Int Healthc Res J. 2021;5(9)OR1-OR4. https://doi.org/10.26440/IHRJ/o509.12447

AUTHOR AFFILIATIONS: (*Corresponding Author)

1. MBBS (India), Medical Student (Aspirant), Greensboro, North Carolina, USA

2. M.PT. and Consultant Physiotherapist, Koonur, Telangana, India

3. BDS, Private Practioners, Pondicherry, India 